\title{
IRISH CARDIAC SOCIETY
}

\section{Proceedings of Annual General Meeting held 20th \& 21st November 1992 in Dublin Castle.}

\section{THE DIAGNOSIS OF MYOCARDIAL INFARCTION (MI) BY 3-D ELECTROCARDIOGRAHIC BODYSURFACE MAPPING \\ C. Cullen, G. MacKenzie, J. Adgey.}

Cardiac Unit, Royal Victoria Hospital, Grosvenor Road, Belfast BT12 6BA.

Three dimensional body surface maps provide more informa tion on the geo-spatial distribution of cardiac electrical activity. I is hypothesised that this information could facilitate the diagnosis of acute MI in early cases where standard methods are equivocal. To date these techniques have been confined to the laboratory and have yet to find clinical application. An important first step is the assessment of their diagnostic value among patients with established MI.

All 82 consecutive patients admitted to the RVH cardiac unit with first presentation of chest pain suggestive of MI were mapped at 24 hours using a Corazonix BSM-32 predictor which measured QRS and STT iso-integrals using 32 leads. Of the 82 patients, 57 (69.5\%) had an initial diagnostic ECG with subsequent confirmatory enzyme elevation. A further $25(30.5 \%)$ presented with non diagnostic ECG findings. Fifteen of this group had an MI a confirmed by an increase in cardiac enzymes. For comparative purposes, 54 controls were recruited and mapped, all with normal ECG and no IHD risk factors. A series of discriminant function analyses were performed to assess sensitivity and specificity. Using a subset of the 32 QRS and the 32 STT iso-integral measure ments, selected by a stepwise forward algorithm, a sensitivity of $94.7 \%(54 / 57)$ and a specificity of $90.7 \%$ (49/54) was obtained. When all measurements were analysed together, better results were obtained: sensitivity $10070(57 / 57)$ and specificity $96.3(42 /$ 54). In further multivariate analysis, map topography differed significantly $(p<0.01)$ between males and females. Separating the data according to sex and using all QRS and STT iso-integral measurements, $100 \%$ specificity and sensitivity resulted. Despite these findings, each of the derived discriminant functions had difficulty in classifying the 25 cases belonging to the possible $M$ group. The best results obtainable were: a sensitivity of $60 \%$ and a specificity of $60 \%$. This suggests that further analysis is required to identify the topography of these patients.

MYOGLOBULIN RELEASE AS AN INDICATOR OF REPERFUSION FOLLOWING THROMBOLYSIS IN ACUTE MYOCARDIAL INFARCTION

F. Lavin, M. Keane, A. Forde, P. Shah, F. Gannon, K. Daly

Department of Cardiology, University College Hospital,

Galway. National Diagnostics Unit, University College,

$$
\text { Galway. }
$$

Myoglobulin (MB) concentration time curves were studied as an index of successful reperfusion in acute myocardial infarction and compared to standard non-invasive indices of reperfusion time to peak CPK, rapid-ST segment normalization, reperfusion arrhythmias. 18 patients with clinical and electrocardiographic evidence of acute myocardial inf arction were studied, of which 12 received thrombolytic therapy. Six patients who received thrombolysis showed signs of early reperfusion - Group A, six patients did not reperfuse - Group B, six did not get thrombolysis
- Group C. Group A were shown subsequently angiographically to have patent infarct related arteries. Blood samples were obtained on admission ( $O$ hrs.), hourly up to $8 \mathrm{hrs}$. and 8 hourly $x 48 \mathrm{hrs}$. Blood was assayed for MB and total CPK. Biochemical indices assessed were time to peak CPK, time to peak $\mathrm{MB}, \mathrm{CPK}$ and $\mathrm{MB}$ index. This index was calculated by $\mathrm{MB}$ and CPK level at $2 \mathrm{hrs}$. $\mathrm{i}$ level at 0 hrs. Myoglobulin index was significantly higher in Group A v Group B (8.36 v 3.45, p $<0.001)$ and in Group A v Group C (8.36 v 1.73, p $<0.001)$. There was no significant difference in MB index between Group B and C. Mean time to peak MB was lower in Group A v Group B $(5.16$ v $8.75 \mathrm{hrs} . \mathrm{p}<0.05)$ and in Group A v Group C ( 5.16 v $8.83 \mathrm{hrs} . \mathrm{p}<0.05)$. CPK index did not allow differentiation between the groups. Mean time to peak MB in the reperfusion Group A was significantly shorter than time to peak CPK $(5.16 \mathrm{v} 12.8 \mathrm{hrs})$.

In conclusion, these findings indicate that at $2 \mathrm{hrs}$. following thrombolysis, MB index is an accurate and early predictor of infarct reperfusion and has significant advantage over CPK. Also time to MB peak allows earlier prediction of reperfusion than time to peak CPK. We feel that MB levels have an important role in th management of patients following thrombolysis in acute myocardial infarction.

INTTIAL EXPERIENCE OF DIRECTIONAL CORONARY ATHERECTOMY FOR THE TREATMENT OF COMPLEX CORONARY ARTERY LESIONS

B. M. McClements, A. J. McNeill, C. M. Wilson, S. W. Webb, N. P. S. Campbell, M. M. Khan.

Regional Medical Cardiology Centre, Royal Victoria Hospital, Belfast

Directional coronary atherectomy (DCA) is a new percutaneous revascularisation technique which is particularly suitable for treatment of eccentric and bulky lesions in large coronary arteries. A small cylindrical mechanical cutting device (DVI) is positioned across the lesion using a guide catheter and guide wire. $\mathrm{A}$ balloon opposite the cutting window holds the device in apposition to the lesion and cuts are made by a blade which moves along the long axis of the device.

We have performed DCA in $18(15 \mathrm{M}, 3 \mathrm{~F})$ patients, mean (SD) age $59 \pm 10$ yrs, via the femoral artery. The site of the lesion was left anterior descending in 12, right coronary artery in 5 and circumflex in 1. All patients were premedicated with aspirin and persantin and dextran was infused during the procedure. Heparin (to maintain the PTTK at 100-200s) and isosorbide dinitrate were infused for 24 hours post-DCA. The guide catheter was size $9.5 \mathrm{~F}$ in $3,10 \mathrm{~F}$ in 10 and $11 \mathrm{~F}$ in 5 and the device used was $5 \mathrm{~F}$ in $7,6 \mathrm{~F}$ in 10 and $7 \mathrm{~F}$ in 1 . The mean volume of contrast used was $274 \pm 118$ $\mathrm{mls}$. In 4 cases preliminary balloon angioplasty was required to facilitate advancement of the device. A mean of $4.9+2$ cuts (range 2-10) were made and a mean of $2.5(2-4)$ pieces of atheroma were obtained. The result was successful (residual stenosis $<50 \%$ vessci diameter) in $15(83 \%)$ cases including one where DCA was performed as an emergency rescue procedure after failed balloon angioplasty. There were 2 procedural failures ( 1 elective DCA. attempted rescue procedure) requiring emergency bypass grafting In one case DCA could not be performed because of guide catheter 
failure but balloon angioplasty was successful. There were no deaths and no arterial wall dissections.

DCA appears to have a high success rate in complex, eccentric coronary lesions where the risk of dissection and abrupt occlusion with conventional angioplasty is substantial.

\section{THE LONG-TERM OUTCOME OF PATIENTS UNDERGOING PTCA DURING EVOLVING MYOCARDIAL INFARCTION}

B. O'Murchu, B. J. Gersh, K. R. Bailey, D. R. Holmes. Mayo Clinic, 200 First Street SW, Rochester, MN 55905

Introduction. Early reperfusion for acute myocardial infarction (MI) results in improved ventricular function and excellent hospital and one-year survival. There is, however, a dearth of data reporting long-term survival ( $>5$ years) after percutaneous transluminal coronary angioplasty (PTCA) performed either as a primary procedure or in conjunction with thrombolytic therapy. Furthermore, few studies have performed risk factor analysis for late events.

Design. We studied 160 patients who underwent PTCA during evolving MI,either with ( $n=101)$ or without $(n=69)$ thrombolytic therapy (streptokinase), between 1981 and 1987.

Results. Mean time to reperfusion was 4.6 hours and patency was achieved in $134(84 \%)$ patients. Mean discharge ejection fraction (EF) was $46 \pm 14 \%$. Coronary artery bypass grafting (CABG) was performed prior to dismissal in 34 patients ( $21 \%$ ) including 21 of 130 patients $(16 \%)$ with single or 2 -vessel disease and 13 of 30 patients (43\%) with triple-vessel disease (pc0.06). Eleven patients (7\%) died in hospital. The 149 hospital survivors were followed for a mean of 69121 months (median 71.7 months). During follow-up, 22 patients (16\%) died, 21 (14\%) had reinfarction, 23 (16\%) underwent CABG, and 21 (14\%) underwent repeat PTCA of the infarct-related artery (IRA). On univariate analysis, age 62, multivessel disease, EF $40 \%$, prior $\mathrm{MI}$, and being a nonsmoker at the time of MI were predictive of late mortality ( $p<0.06$ each yariable). Seven-year survival was $86 \%$ for patients with an open IRA and $67 \%$ with a closed IRA. On multiv ariate analysis, only EF $40 \%$ and prior MI were predictive of late death. The late survival of parients who underwent CABG prior to dismissal was equivalent to that of those who did not.

Conclusions. Therefore, in patients treated with PTCA for acute MI, late survival is excellent. Early surgical revascularization of high risk patients may contribute to these encouraging results.

\section{PREDICTABILITY OF MAJOR ADVERSE CARDIAC EVENTS FOLLOWING PTCA FROM CLINICAL PARAMETERS AND QUANTTTATTVE AND QUALITATTVE ANGIOGRAPHIC ANALYSIS, \\ D. P. Foley, W. R. Hermans, B. J. Rensing, J. Vos, J-P Herrman, P. W. Serruys.}

Thoraxcenter, Erasmus University Ee 2332, P0 Box 1738, 3000 DR Rotterdam, Netherlands.

Major procedural and in-hospital adversecardiac events (MACE) death, non-fatal myocardial infarction, coronary artery bypass grafting or necessity for re-intervention) occur in $2-10 \%$ of all patients undergoing percutaneous transluminal coronary angioplasty (PTCA). This study examines the predictability of these events from clinical parameters as well as baseline and post-
PTCA quantitative and qualitative lesion morphology in 1442 patients treated by PTCA in two European multicenter clinical trials. All cinefilms were analyzed in a core laboratory (using an interpolated edge detection technique-CAAS) for absolute luminal dimensions, lesion length, symmetry, roughness, plaque area, vessel curvature and inflow and outflow angles, as well as for qualitative feanures [pre-PTCA lesion location (vessel and segment), lesion type (AHA/ACC and modified Ambrose classification), location at/in/near a branch point or in a curve $>45^{\circ}$ calcification, presence of thrombus or dissection (NHLBI classification)] by 2 blinded experienced obscrvers. To facilitate statistical comparisons, patients who suffered a major adverse cardiac evert (MACE: $5 \%, n=69$ ) were randomly matched 1:3 with patients who did not experience MACE. Odds ratios (OR) for predictability of MACE were calculated for 42 relevant variables, and in stepwise logistic regression analysis (LR) the following variables, with $O R>2$ and lower $95 \%$ confidence Interval $>1$, were retained in the model:

$\begin{array}{lcccc}\begin{array}{l}\text { Variable } \\ \text { Retained } \\ \text { in LR }\end{array} & \begin{array}{c}\text { MACE/no. } \\ \text { pts.pos.for } \\ \text { variable }\end{array} & \begin{array}{c}\text { MACE/no. } \\ \text { pts.neg.for } \\ \text { variable }\end{array} & \begin{array}{c}\text { Odds } \\ \text { Ratio }\end{array} & \text { (95\% CI) } \\ \text { Dissection } & \mathbf{3 8} / 88 & 16 / 133 & 5.55 & (2.84-10.9) \\ \text { Unstable angina } & 29 / 69 & 39 / 206 & 3.11 & (1.72-5.61) \\ \text { Type "C" lesion } & 12 / 27 & 32 / 134 & 2.55 & (1.08-6.01) \\ \text { Bend > 45 } & 25 / 11 & 31 / 152 & 2.12 & (1.13-3.97)\end{array}$

Conclusion: Comprehensive baseline pre-interventional quantitative lesion morphological assessment failed to identify subsets of patients at particular risk of MACE during or after coronary balloon angioplasty. Angiographically visible dissection immediately after angioplasty was, perhaps not surprisingly, the strongest predictor of Mace. The only pre-procedural variables associated with a greater likelihood of subsequent major adverse cardiac events were unstable angina preangioplasty, Type $C$ lesions and lesion location In a bend $>45^{\circ}$.

EFFECT OF BETABLOCKADE ON INTRACELLULAR ELECTROLYTES AND VENTRICULAR ARRHYTHMIAS IN ACUTE MYOCARDIAL INFARCTION

F. Lavin, P. Shah, A. Mannion, J. Finn. H. Grimes, K. Daly.

Departments of Cardiology and Biochemistry, University College Hospital, Galway.

Ventricular arrhythmias early in acute myocardial infarction (AMI) may be related to circulating catecholamines and their effect on intracellular electrolyte levels. We have carricd out a randomised double blind placebo controlled trial to assess the effect of carly betablockadc on lymphocy ic magnesium (MG) and po tassium (K), serum MG, urinary catecholamines and ventricular arrhythmias in the first $\mathbf{4 8} \mathrm{hrs}$. following acute myocardial infarction. 12 patients with AMI were randomised to receive betablockade or placebo. Metoprolol $15 \mathrm{mg} . I$.V. or placebo was given on admission, followed by oral Metoprolol $50 \mathrm{mgs}$. b.d. or placebo for 48 hrs. Lymphocytic MG, K and serum MG were measured on admission, at 24 and $48 \mathrm{hrs}$. Urinary catecholamines were measured 0-12 and 12-24 hrs. following admission $24 \mathrm{hr}$. ECG and holter recording was carried out to assess ventricular arrhythmias. Six patients had ventricular arthythmias in the first 24 hrs. post AMI, 3 in the active group and 3 in the group recciving placebo. 6 patients had no arrhythmias. Mean lymphocytic $M C$ showed no significant difference between the placcbo and the active groups at 0,24 or $48 \mathrm{hrs} .(70.2,66.9,66.2$ v 70.2, 74,6,75.0 Umol/gm.NS), likewise lymphocytic $\mathrm{K}$ showed no change be- 
tween the placebo and active groups $(778,616.6,638$ v 616719.3 , $666 \mathrm{Umol} / \mathrm{gm} . \mathrm{NS}$ ). Serum MG remained unchanged in both groups over the $48 \mathrm{hrs}$. Similarly betablockade had no apparent effect on either adrenaline or non-adrenaline urinary levels over 0-12 or 12 24 hrs.

This pilot study did not show a relationship between intracellular electrolyte levels and ventricular irritability early post M.I. Equally early administration of betablockade was not successful in sup. pressing ventricular irritability. The results suggest that the proven beneficial effects of betablockade may be due to factors occurring at a later stage post infarction.

\section{CORONARY ARTERY BYPASS GRAFT SURGERY IN ELDERLY PATIENTS}

M. Lonergan, O'Donnell, L. Daly, E. McGovem, I. Graham Irish Cardiac Surgery Register and participating Cardio-thoracic Surgeons, National Cardiac Surgery Units.

The proportion of patients aged over 70 years who have coronary artery bypass graft (CABG) surgery in Ireland has increased from 1.0\% of patients in 1984 to $11.0 \%$ of patients in 1991. In this 8 year period 386 patients [289 males and 97 females] had primary isolated $\mathrm{CABG}$ surgery. Mean age was $72.8 \pm 2.5$ years [Range 70 . 84]. Angina severely limited activity in $84.0 \%$ of patients, $9.0 \%$ had a recent myocardial infarction prior to surgery, $15.5 \%$ had left ventricular failure, $13.5 \%$ had moderate to poor left ventricular function and $12.4 \%$ had poor distal coronary arteries. In-hospital mortality as $5.9 \%$ and as significantly greater in patients with diminished left ventricular function $\left[\mathrm{p}=0.033^{*}\right]$ and in those with poor distal coronary arteries [ $\left.\mathrm{p}=0.032^{*}\right]$. Mortality was higher in males than females $[6.5 \%$ vs $4.1 \% ; \mathrm{ns}]$ and also in those patients who had an internal mammary artery [IMA] graft compared with those who had vein grafts only $(7.2 \%$ vs $5.0 \% ; n s)$. In patients aged under 70 years who had CABG surgery during this period [n=6917, mortality was higher for females than males $[3.1 \%$ vs $2.1 \%$; $\mathrm{p}=0.057 \mathrm{~ns}]$ and was lower in patients who had an DMA graft than those who only had vein grafts $[1.6 \%$ vs $4.1 \% ; \mathrm{p}<0.0001]$. In both age groups patients who had vein grafts only were ore symptomatic and had ore clinical and investigative manifestations of their coronary artery disease than had those patients in who an IMA graft was used. The differing results in patients over 70 in relation to sex have been noted in other studies. How ever, results in relation to the use of IMA graft in this age group while non-significant differ from other reported studies and we feel that they require continued monitoring and more study.

[* chi-squared tests ]

EXERCISE ECHOCARDIOGRAPHY (EE) WITH MULTIPLE FILTERING TECHNIOUES: DETECTION OF EXERCISEINDUCED REGIONAL MYOCARDIAL DYSFUNCTION AND COMPARISON WITH ST-SEGMENTS ON ECG

\section{P. A. Joseph, K. Robinson, T. Kinsella, P. Crean,} G. Gearty, M. Walsh

Department of Cardiology, St. James's Hospital, Dublin 8 .

EE with multiple filtering techniques is a new development in image processing for the detection of myocardial ischaemia. Stress ECG is widely used as a non-inv asive tool to assess patients with CHD. In order to compare these 'investigational' techniques, 70 patients (pts), (Males 48, Females 22, Mean age 52.819.3 years), with stable angina of effort were studied. Abnormalities of scg. mental wall motion (WM) and thickness on EE and ST-segment changes on ECG suggesting myocardial ischaemia were compared with coronary angiography.

EE detected abnormal WM and thickness in 56 of 62 pts with significant coronary artery disease (sensitivity $90 \%$ ). All 8 with normal angiograms had normal findings on $\mathrm{EE}$ (specificity $100 \%$ ). The pts with single and multivessel disease were evaluated separately. EE detected abromal WM and thickness in 30 of 35 (85.9\%) pts with single vessel disease, and in 26 of $27(96 \%)$ pts with multivessel disease. The concordance of EE findings with those on angiography of the left coronary artery was $91 \%(\mathrm{p}<0.001$ $\mathrm{k}=0.823$ ) and of the posterior descending artery was $85.7 \%$ $(\mathrm{p}<0.001, \mathrm{k}=0.720$ )

On stress ECG, ST-segment changes were detected in 31 of 62 pts with significant coronary artery disease' (sensitivity 50.8\%) and 5 of 8 pts with normal angiograms had normal findings (specificity 62\%). For single vessel disease, 13 of $35(37 \%)$, and for multivessel disease 18 of $27(70 \%)$ had STsegment changes. The concordance of stress ECG findings with those on angiography of the left coronary artery, was $59 \%(\mathrm{p}=0.180, \mathrm{k}=0.159)$, and of the posterior descending artery was $50 \%(\mathrm{p}=0.009, \mathrm{k}=0.022)$.

EE with multiple filtering techniques is highly sensitive and specific in detecting underlying coronary artery disease. It may provide a more satisfactory noninvasive alternative than stress ECG.

VITAMIN B6 AND FOLATE REDUCE HOMOCYSTEINE CONCENTRATIONS IN CORONARY ARTERY DISEASE

M. Ryan, K. Robinson, R. Clarke, R. Refsum, P. Ueland, I. Graham.

Dept. of Cardiology, The Adelaide Hospital, Peter Street, Dublin.

Hyperhomocysteinaemia is a risk factor for vascular disease and is most often due to cystathionine synthase deficiency. Vitamin B6 is an essential cofactor for this enzyme and folic acid is also required for the remethylation of homocysteine to methionine. Deficiency of both of these may be responsible for elevated homocysteine levels.

Twelve (10M,2F, mean age $45 \pm 5$ years) patients with documented coronary heart disease received oral $\mathrm{B} 6$ and folate supplements for 4 weeks in a double-blind, cross-over placebo controlled study. Peak total homocysteine was measured prior to, and following, each treatment period.

$\begin{array}{ccc}\text { Serum homocysteine concentration (nmol/L) } \\ \text { Baseline } & \text { Placebo } & \text { Active } \\ 34.5 & 33.7 & 27.0^{*}\end{array}$

*P<0.0004 baseline vs both baseline and placebo. There were n side effects. In patients with premature coronary artery disease treatment with vitamin B6 and folate rcduces elevated homocysteine levels. This innocuous therapy may have an important role in the treatment of patients at increased risk of premature vascular disease.

AN OESOPHAGEAL APPROACH TO RESUSCITATION

D. J. Cochrane, A. J. Stewart, D. J. McEneaney, J. D. Allen, J. Anderson, G. Dempsey, A. A. J. Adgey.

Regional Medical Cardiology Centre, Royal Victoria Hospital, Belfast BT12 6BA.

Since the highest incidence of bradyarrhythmia with hypotension and asystole complicating acute myocardial infarction occurs 
early after the onset of symptoms, we have developed a noninvasive method of ventricular pacing using the oesophagus (O) Also using the 0 , a satisfactory method of electroventilation (EV) has been determined. Unipolar esothoracic pacing (EP) and gas trothoracic pacing (GP) (current (I) passes from a point source, positioned in either the distal $O$ or stomach respectively, to a chest wall pad) and bipolar pacing using an $O$ catheter (Vygon) were compared. In 17 parients (pts), ventricular capture was achieved using GP in $16(94 \%)$ and EP $16(88 \%)$ but GP required less I $(15.0$ mA \pm SD 7.6 V8 24.1 mA + SD 8.8). In 20 pts, EP was successful in $18(90 \%)$ compared with 7 (35\%) using bipolar pacing. Optimal ventricular capture occurred using $60 \mathrm{~ms}$ I and a mean threshold I of $16.0 \mathrm{~mA}$ with a unipolar GP electrode inserted to an average depth of $44.2 \mathrm{~cm}$ from the lower lip, together with a high impedance chest pad (250) in the 4 th interspace at the left stemal edge.

The stimulated tidal volume (TV) produced when short duration pulses $(0.1 \mathrm{~ms})$ are applied between 2 axillary chest wall pads (transchest EV (TCEV)) together with that produced when the pulses are passed from the same pads to an $O$ electrode (trans $O E V$ (TOEV)) at various insertion depths in the $O$ were compared. Apnoeic pentobarbitone anaesthetised pigs were ventilated and a pneumotachograph connected to the endotracheal tube. A stimulator produced trains of pulses with variable voltages (20-120V), frequencies $(12-375 \mathrm{~Hz})$ and durations $(0.6-1.8 \mathrm{~s})$. At voltages $>60 \mathrm{~V}$, TOEV produced significantly greater TV's than TCEV (at $100 \mathrm{~V}$, $610 \mathrm{vs} 211 \mathrm{ml} p<0.01$ ). The optimum route of $E V$ is via the $O$ using a pulse frequency of $40 \mathrm{~Hz}, 0.7 \mathrm{~s}$ duration with the $O$ electrode sited proximal to the gastro- $O$ junction. Thus a dual purpose gastro-O catheter can achieve satisfactory ventricular pacing and $\mathrm{EV}$.

\section{QUALITY OF LIFE AFTER SURGICAL PALLIATION FOR COMPLEX CONGENITAL HEART DESEASE}

\section{F. A. Casey, H. C. Mulholland, B. G. Craig, R. Power,} N. Rooney

Dept. of Paediatric Cardiology, Royal Belfast Hospital For Sick Children, Belfast, N. Ireland.

Dept. of Clinical Psychology, Queens University, Belfast.

As the frontiers of cardiac surgery are advanced, even children with complex cyanotic congenital heart disease previously considered inoperable are now having palliative surgery in an attempt to prolong life. Does this merely prolong a miserable life for the child? The aim of this study was to evaluate the results of such surgery in terms of the quality of life for the child. A complete physical and psychosocial assessment was performed on twenty six children with surgically palliated complex congenital heart disease.

Physical assessment included analysis of symptoms, growth, activity and formal exercise testing. Social competence, behaviour, and educational difficulties were studied using the Achenbach Child Behaviour Checklist. An age and sex matched control group of twenty six children with innocentmurmurs was evaluated by the same protocol.

The majority of the study group had moderate limitation of exercise tolerance (mean maximal exercise time 7.1 minutes) with three patients having severe limitation of exercise. Two children were unable to attend school, $8(31 \%)$ attended part-time and 16 (62\%) attended full-time. Behavioural disturbance was found in $22 \%$ of the study group as compared to $6.9 \%$ of controls ( $p<0.05$ ). In particular those with complex heart disease displayed social withdrawl $(p<0.001)$, but not depression or diminished selfesteem.
Conclusions: Palliative surgery had enabled most patients to function with moderate physical disability. Social isolation may be a problem for this group of patients and it should be the aim of parents, teachers and paediatric cardiologists to encourage as much integration in normal social and physical activities as is reasonably possible.

\section{RADIO FREQUENCY ABLATION FOR CONTROL OF PAROXYSMAL TACHYCARDIAS}

D. B. O'Keeffe, J. McComb, C. Wilson.

Belfast City Hospital, Freeman Hospital and Royal Victoria

$$
\text { Hospital. }
$$

Ten patients ( 8 female, 29 to 61 yrs) with paroxysmal SVT had RF ablation treatment. All had multiple hospital admissions for disabling SVT and failed treatment with antiarrhythmic drugs including amiodarone. Diagnoses were WPW syndrome (5), A-V nodal tachycardia (2), SVT using concealed V-A conduction (1) and paroxysmal atrial flutter/fibrillation (AF) (2). An Osypka HAT 200 RF machine was used with Polaris catheters. Procedures lasted 30 to $300 \mathrm{mins}$, and up to $9 \times 30 \mathrm{sec}$. deliveries of $30-40$ watts RF energy were used. Local anaesthesia and sedation were used. Three patients had minor chest discomfort during energy delivery. Six accessory pathways were mapped and 5 ablated. One anteroseptal pathway could not be ablated. $\mathrm{A}-\mathrm{V}$ block was achieved in both cases of $A F$ and pacemakers implanted. Selective slow pathway ablation was obtained in the 2 intra $A-V$ nodal tachycardias. No serious complications occurred. Efficacy was established by repeat EPS with failure to start tachycardia, $\mathrm{i} / \mathrm{v}$ adenosine to give transient A-V block or by evident permanent complete A-V block

Conclusions: Catheter RF ablation was safely usedto give permanent cure of refractory SVT in 9 of 10 patients. The procedure may be prolonged and requires electrophysiological experience, but offers permanent cure without open heart surgery and has become the treatment of choice for refractory or malignant supraventricular tachycardias.

\section{ATRIAL FIBRILLATION IN MIDDLE AGE: IMPLICATIONS FOR PROGNOSIS AND ANTICOAGULATION}

K. Robinson, K. S. Tan, C. Pye, N. McCabe, N. Hickey, I. Graham, M. Walsh. Irish Heart Foundation, Dublin 4.

Atrial fibrillation (AF) has been associated with an increased risk of systemic thromboembolism. Since 1968, the Irish Hear Foundation has screened over 160,000 middle-aged individuals for risk factors for premature vascular disease. 189 patients (pts) with AF have been documented by ECG (prevalence $0.1 \%$ ). Pts were older than the mean age for the study group $(57.0+111.1 \mathrm{vs}$ $40.9+10.2 \mathrm{yr}, p<0.001)$ and had higher mean systolic and diastolic blood pressure $(143.0+20.6$ vs $131.4+15.7$ and $90.1+11.1$ vs $81.7+9.7 \mathrm{mmHg} . \mathrm{p}<0.001$. To define long-term mortality and morbidity, pts were compared with controls in sinus thythm matched for age, sex, blood pressure, smoking patterns, serum cholesterol concentration and underlying heart disease

During mean follow-up of $6.5+6.2$ (median 3.0 ) yr, 8 of 48 (16.6\%) pts with AF followed to date have died in comparison to 4 of $49(8.2 \%)$ of controls followed for a similar period. Heart disease became manifest during follow up in 11 of 43 patients with AF but in only 3 of 44 controls ( $p<0.05$ ). Only one stroke has been observed to date in the whole study group. 
AF is rare in middle age. Pts are older and have higher BP than controls. During long term follow-up; pts with AF manifest more cardiac disease than controls and may have an increased mortality rate. The risk of stroke, however, may be less than previously thought. The latter may limit the need for chronic anti-coagulation except in selected high-risk cases.

\section{NON-INVASIVE DUAL CHAMBER PACING USING A NOVEL HEXAPOLAR GASTRO-OESOPHAGEAL ELECTRODE}

D. McEneaney, D. Cochrane, J. Anderson, J. Adgey. Cardiac Unit, Royal Victoria Hospital, Belfast, N. Ireland.

Transcutaneous non-invasive cardiac pacing has several inherent disadvantages - low success rate, high current requirements, lack of atrioventricular (AV) sequential pacing capability, and poor patient tolerance. We have developed a new hexapolargastrooesophageal (GO) electrode which allows separate atrial, ventricular and AV sequential pacing and recording. The electrode is passed into the stomach under light sedation and positioned in the gastric fundus by withdrawing the steerable tip until it meets the resistance of the GO junction. Unipolar ventricular pacing is performed using a point source mounted distally on the electrode tip and a high impedance chest pad placed medial to the apex. Five ring electrodes mounted proximally on the GO electrode are used for simultaneous bipolar atrial pacing and recording. A new portable pulse generator permits separate atrial, ventricular and AV sequential pacing in fixed rate or demand mode with variable currents (range 0-50 mA) pulse durations (atrial 3-21 msec, ventricular $10-40 \mathrm{msec})$ pacing rates $(40-160 / \mathrm{min})$ and $A V$ delays $(50$ $250 \mathrm{msec}$ ). Using this pacing system in 36 patients ( 21 male, 15 female average age 69.8yrs.SD 13.5) with bradyarrhythmias (14 sinus node dysfunction, 12 sinus bradycardia, 9 complete heart block, 12:1 AV block) stable atrial, ventricular and AV sequential pacing were easily established in 34(94\%); pacing was maintained for upward on $\mathbf{3 0}$ minutes. Mean threshold current requirements for atrial and ventricular capture were $15.0 \mathrm{~mA} \pm$ SD5.4 and $22.7 \mathrm{~mA}+\mathrm{SD} 9.0$ at pulse dur ation of $9 \mathrm{msec}$ and $40 \mathrm{msec}$, respectively. The gas tro-oesophageal electrode was easily tolerated; no complications occurred. This pacing system may be useful in the elective electrophysiological evaluation of patients with possible conduction disturbances, in the assessment of anti-arrhythmic drug efficacy and for emergency AV sequential pacing during acute bradyarrhythmias.

RADIO FREQUENCY CATHETER ABLATION OF INCESSANT, MEDICALLY RESISTANT

SUPRAVENTRICULAR TACHYCARDIA IN INFANTS AND SMALL CHILDREN

P. C. Oslizlok, C. L. Case, P. C. Gillette, Barbara J. Knick, L. P. N. Henry, L. Blair.

Medical University of South Carolina, South Carolina

Children's Heart Centre, Division of Pediatric Cardiology,

71 Ashley Avenue Charleston, South Carolina 29425

Radiofrequency catheter ablation of incessant, medically resistant supraventricular tachycardia in infants and small children.This study retrospectively evaluates initial experience with Radio frequency catheter ablation in a group of seven infants and small children with a history of incessant, medically resistant supraventricular tachycardia. Prior to attempted catheter ablation, all patients had failed conventional medical therapy (digoxin-and or propranolol) and, in addition, each continued to have daily episodes of supraventricular tachycardia while taking amiodarone or a IC agent alone or in combination. The average patient age was 10 months (range 1-27) and the average patient weight was 6 kilograms (range 3-13). Electrophysiologic diagnosis included reentrant supraventricular tachycardia in 6 patients and atrial ectopictachycardia in 1 patient. These 7 patients underwent a tota of 9 catheter ablation procedures. The atrial approach to ablation was employed in 8 of the 9 procedures. Overall, total success of Radio frequency catheter ablation was accomplished in $5 / 7$ patients, partial success in $1 / 7$ patients, and failure in the remaining patient. The combination of radio frequency catheter ablation and surgical ablation was successful in tachycardia control for al patients; with at least five months of follow up, no patients has had a recurrence of supraventricular tachycardia or a reappearance of a delta wave.

In conclusion, surgical ablation of arrhythmogenic substrates in this age group, al though rarely indicated, has been found in the past to be safe and effective. This initial experience with radio frequency catheter ablation in infants and small children demon strates that this procedure is a promising nonpharmacologic therapeutic alternative to surgical ablation.

\section{THE ROLE OF SURGERY IN THE MANAGEMENT OF PATIENTS WITH VENTRICULAR TACHYARRHYTMIAS AFTER MYOCARDIAL INFARCTION}

T. Gumbrielle, J. P. Bourke, C. J. Hilton, R. W. F. Campbell. Department of Academic Cardiology, Freeman Hospital, Newcastle, U.K.

The eradication of arrhythmia is the ultimate therapeutic goal in patients with recurrent ventricular tachyarrhythmia [VTA] after myocardial infarction [MI] . Although this may be achieved by map-guided endocardial resection [ER], many consider the overall surgical risk for these patients too high and the technique remains under utilised. The aim of this analysis was to define the risk of ER in clinically distinct patient subgroups by relating outcome to the clinical context in which surgery was performed. In the period 1980-1991, ER was offered to 100 patients referred to this unit with life-threatening, drug refractory arrhythmias regardless of age, time from acute MI or ventricular function. Мear age was 56 \pm 10 years, 81 were male and the infarction was anterior in 71 patients. Mean left ventricular ejection fraction was $28 \%$ (range 5 $50 \%$ ) and 60 patients had a left ventricular aneurysm. The mean number of major VTA episodes was 11 (range 2-200) and drug failures $4 \pm 2$ per patient respectively. Emergency surgery for intractable VTA was required in 28 patients and 32 patients had surgery within eight weeks of MI ("early"). ER of uniform technique was performed in all patients, aneurysmectomy in 57 , cryoablation in 26 and antiarrhythmic ventriculotomies in 11. Twenty five patients died within 30 days of surgery -21 in low output cardiac failure. There were no post-operative deaths from arrhythmia and only six required antiarryhthmic therapy. Outcome within 30 days of ER was critically related to the clinical context in which surgery was undertaken. Mortality rates for elective ER more than eight weeks after MI, "early" ER after M1, emergency ER and "early" emergency ER were $18 \%, 34 \%, 46 \%$ and $56 \%$ respectively. Actuarial survival rates for the total group at 1,3 and 5 years after surgery were $70 \%, 68 \%$ and $66 \%$ respectively. The high overall mortality reflects the type of patients undergoing ER. 
Surgery offers VTA cure at a risk proportional to the patients preoperative risk of sudden death. It has unique role in patients with intractable VTA and has yet to achieve it's full potential.

\section{SUDDEN DEATH SURVEY}

P. P. Kearney, F. Fennell, S. McKieman, W. Fennell. Department of Cardiology, Cork Regional Hospital, Cork

This survey aimed to define the characteristics of people dying from probable cardiac sudden death (CSD) and to determine the level of awareness of close relatives of the risk factors and symptoms of ischaemic heart disease (IHD) and CSD.

A questionnaire was circulated to relatives of persons, living in the Southern Health Board aree (Cork and Kerry) whose death was announced in the local daily newspaper as being sudden or unexpected, from the start of October 1990 to the end of September 1991. 593 questionnaires were sent and $330(59 \%)$ replies received. $91 \%$ of deaths registered by the Central Statistics Office for this period were announced by the paper.

124 persons died in less than 1 hour of the onset of symptoms. Of these, 25 were identified by respondants as myocardia infarctions and in 84 no cause of death was specified. This group was analysed for age, sex, presence of cardiac risk factors, and relatives' awareness of risk factors and symptoms. 49 persons were identified who had experienced new onset chest pain or 'indigestion' prior to their death, died within 24 hours and had no prior history of IHD. The majority of this group were smokers $(61 \%)$, and almost half of them were hypertensive (46\%). A lack of awareness was seen among relatives of the deceased of how cardiac disease might present ( $64 \%$.) and what constituted risk factors for IHD (less than $2 / 3$ of respondants volunteered one risk factor). Data from the coroner's office and death certificates in the case of hospital deaths was compared with data recieved from the questionnaires.

We identified a substantial group who ignored or misinterpreted premonitory symptoms prior to their CSD. We found a striking lack of awareness of the modes of presentation and risk factors for IHD and CSD amongst relatives of those dying. A national educational program to redress this deficit may lead to the prevention of a number of CSDs both by population risk factor modification and by facilitating earlier presentation to medical attention of those with newly symptomatic IHD.

CORONARY RESTENOSIS FOLLOWING

PERCUTANEOUS INTERVENTIONS. WHAT IS THE INFLUENCE OF THE VESSEL SIZE

D. P. Foley, J. Escaned, W. R Herrnans, V. A. Umans, P. P. de Jaegere, P. J. de Feyter, P. W. Serruys.

The Thoraxcentre, Erasmus University EE 2332, PO Box 1738, 3000Dr Rotterdam, Netherlands.

Coronary arterial renarrowing ("restenosis") following percutaneous transluminal revascularization therapy remains the grcatest limitation of this approach to the treatment of obstructive coronary disease. Current knowledge indicates that restenosis is a ubiquitous fibroproliferative response to unavoidable arterial wall injury caused at intervention, and is a normally distributed phenomenon occurring to some degree in virtually all treated lesions. Little is known, however, regarding the potential influence of the size of treated vessels on the extent of renarrowing following intervention. The purpose of this study is to evaluate the effect of vessel size on luminal renarrowing following coronary revascularization by 4 different devices, using a validated quantity coronary angiographic analysis system (CAAS).

Methods and Results. To consider luminal renarrowing in a continuous fashion and to facilitate comparisons between various devices used in vessels of different sizes, the recently introduced measurements of relative gain (RG) and relative loss (RL) in minimal luminal diameter (MLD) are employed to ev aluate immediate and long term angiographic outcome. RG is the improvemen in MLD) achieved at intervention and RL the deterioration during follow-up, normalized for vessel size. The study population comprises patients undergoing successful balloon angioplasty (BALLOON $n=1234$ ), directional atherectomy (DCA, $n=120$ ), implantion of self-expanding stainless steel mesh (WA STENT, $\mathrm{n}=104$ ), or balloon expandable tantalum coil stent (WIK STENT, $\mathrm{n}=100$ ). Graphic display of the angiographic measurements reveals a definite pattem of decreasing relative loss in MLD with increasing vessel size for balloon angioplasty, DCA, and balloon expandahle stent. The corresponding relative gain in MLD at intervention is seen to decrease, virtually in parallel with relative loss during follow up. Although the pattern is different for the self expanding stent (WA STENT), the relative loss again mirrors the relative gain.

Conclusion : Restenosis after interventions, as evaluated using the continuous approach of relative loss in minimal luminal diameter, tends to diminish with increasing vessel size and may, at least partly, be explained by decreasing relative gain in larger vessels. These finding are in agreement with pathological and experimental evidence and may be interpreted as representing the angiographic manifestation of relatively less extensive neointimal formation in largervessels, in response to lesser degrees of wall injury imparted at intervention.

\section{LATE ANGIOGRAPHIC FOLLOW-UP OF PALMAZ SCHATZ INTRACORONARY STENT INSERTIONS}

J. Galvin, S. Leavey, D. Sugrue.

Dept. of Clinical Cardiology, Mater Hospital, Dublin 7.

Restenosis rates of up to $40 \%$ at 3 months following Percutaneous Transluminal Coronary Angioplasty (PTCA) have prompted the development of intracoronary stents to maintain long-term patency. The Palmaz-Schatz balloon-expandable intracoronary stent is a fenestrated, stainless steel device, $15 \mathrm{~mm}$ long and articulated in the middle.

Although several trials have shown restenosis rates of 20-30\% at 4-6 months, long-term patency is still relatively unknown. We now report a full selies of late angiographic follow-up at 13.4 months on patients who underwent Palmaz-Schatz stent insertion.

Eleven patients ( 8 men, mean age $50 \mathrm{y}$. and three women, mean age 59.7 y.) reccived intracoronary stents. Eight had proximal LAD lesions, two had mid-LAD) lesions and one had a RCA lesion. Ten of the patients had previous PTCAs which had failed and one had stent insertion as the primary procedure.

The stent was successfully deployed in ten of eleven cases - one case required emergent CABG following balloon rupture during the procedure. In one case, vessel acclusion was noted five days following the procedure in the segment immediately distal to the stent and the patient is currently awaiting elective CATBG. Of the remaining nine pts., only onc patient was found to have restenosis which was $50 \%$ at 2 months and he subsequently had CABG for two vessel disease. 
The other eight patients (73\%) had widely patent stents angiographically at a mean of 14 months (3-34 months) following the procedure.

In this series, late restenosis beyond two months was not a problem although problems with stent deployment and early restenosis remain significant.

\section{ASSESSMENT OF CARDIAC FUNCTION USING A NEW IMAGING TECHNIQUE AND TANTALUM-178}

S. R. Vallely, N. P. S. Campbell, J. D. Laird, R. Ferguson,

$$
\text { S. Duff. }
$$

Royal Victoria Hospital, Belfast.

This purpose of this investigation was to validate a new cardiac imaging system for radionuclide angiocardiography against a conventional single crystal camera and Technetium- $99 \mathrm{~m}$. The new system consists of a multiwire camera which has count rate capabilities similar to multicrystal gamma cameras and a short lived radionuclide, Tantalum-178 $(\mathrm{tl} / 2=9.3 \mathrm{mins})$. The isotope generator is housed within the camera unit creating a fully mobile unit.

For our initial assessment of the system 40 patients underwent supine measurement of ventricular function at rest by gated blood pool imaging with a single crystal camera and Technetium- $-99 \mathrm{~m}$ (Tc $99 \mathrm{~m}$ and by first pass angiography using a multiwire camera and Tantalum-178. In addition 27 of these patients had first pass angiography using the single crystal camera and Technetium- $99 \mathrm{~m}$ (Tc-99m). Each patient had all investigations performed within a period of two weeks and with no change in medication.

Left ventricular ejection fractions using the multiwire system demonstrated a significant correlation with those obtained by gated blood pool imaging $(r=0.89, p<0.001)$ and with those obtained by conventional first pass angiography $(r=0.74, p<0.001)$ The correlation coefficient between the conventionally obtained gated blood pool and first-pass images was 0.78 ( $p<0.001)$. The average dose of isotope with the multiwire system was $1336 \mathrm{MBq}$ (range 407-2923MBq) and with the conventional system 555MBq. With these doses of isotope the effective radiation dose for the multiwire camera was lower by a factor of 8.2. Average counts in the left ventricular end diastolic frame increased by a factor of 21.4 with the multiwire camera when compared to conventional single crystal first-pass angiography (from 374 to 5694).

We conclude that the multiwire system accurately assesses ventricular function whilst offering major advantages in terms of improved patient dosimetry.

\section{CIRCADIAN VARIATION OF TISSUE PLASMINOGEN ACTIVATOR AND ITS INHIBITOR IN MEN WITH ISCHAEMIC HEART DISEASE}

\section{A. B. Bridges, T. H. Pringle, G. P. McNeill, M. McLaren,} J. J. F. Belch.

Department of Medicine, Ninewells Hospital and Medical School, Dundee, DDI 9SY, Scotland, U.K.

A circadian variation in the fibrinolytic activity of blood has been reported in normal volunteers and patients with myocardial infarets and unstable angina. This circadian variation in the throm- botic tendency is said to contribute to the increased incidence of thrombotic events in the morning. No one however, has investigated circadian variations in tissue plasminogen activator antigen (tPA Ag) or plasminogen activator inhibitor (PAI) activity in patients with stable ischaemic heart disease (IHD). We therefore studied the circadian variation of $\mathrm{PA} \mathrm{Ag}$ and PAI activity in ten men with stable IHD on no regular dng therapy. Seven blood samples were collected at four hourly intervals from 12:00 unti the same time the following day. The subjects were ambulant from 08:10 until 00:00 at which time they went to bed. They remained in bed until 08:00 the following morning. PAI levels had a significant circadian variation (pcO.001), peak levels occurred at 04:00 and trough levels at 20:00. These results demonstrate similar circadian patterns to those of normal volunteers. However, our data indicates for the first time that a significant circadiar variation of PAI levels exists in patients with stable IHD which predisposes to thrombosis in the early moming hours. Furthermore, interestingly, tPA Ag levels did not vary significantly during the study period which is in contrast to our results obtained in normal volunteers. This observation suggests patients with IHD are at risk early in the morning through both a rise in PAI levels and failure of increase in tPA Ag levels.

\section{CATHETER INTER VENTIONS IN ADULT CONGENITAL HEART DISEASE}

L. O'Sullivan, H. Bain, S. Hunter, C, Wren

Freeman Hospital, Newcastle upon Tyne, England. NE7 7DN.

Catheter intervention has revolutionised the treatment of many forms of congenital heart disease. Congenital heart disease may present in adult life and there is continuing debate over whether they are best managed by adult or paediatric cardiologists. We have reviewed the results of all the nonsurgical interventions for both paediatric and adult patients for the Northern Region which has a catchment area of over three million people.

The interventions most frequently performed are transvenous closure of patent ductus arteriosus (PDA), balloon dilatation of coarctation of the aorta ( $\mathrm{CoA}$ ), pulmonary valve (PV) and aortic valve (AV). Eight adults have undergone transvenous closure of PDA (age range $16-56$ years). Large devices $(17 \mathrm{~mm}$ ) were used initially in three, three patients required more than one device to achieve complete closure. Sixteen patients underwent balloon dilatation of $\mathrm{CoA}$ (age range 132 years). They were all native coarctations. The mean gradient pre-procedure was $28 \mathrm{mmHg}$ and post procedure was $3 \mathrm{mmHg}$. Fifteen patients had pulmonery balloon dilatation (age range 16-66). The mean gradient prior to dilatation was $54 \mathrm{mmHg}$ and post dilatation was $25 \mathrm{mmHg}$. Five patients required double balloon insertion to achieve adequate dilatation. Aortic valve dilatation was carried out in nine patients (age range 16-35 years). The mean gradient pre-dilatation was 67 $\mathrm{mmHg}$ and post dilatation was $23 \mathrm{mmHg}$. The mean balloon size was $21 \mathrm{~mm}$.

Interventional catheterisation is technically demanding and results will depend largely on the expcrience of the operator. The demand for non-surgical intervention in adults with congenital heart disease in a population similar to that of the Republic of Ireland is about eight procedures per year. Because of the relar tively low numbers they are best treated by a paediatric cardiolo. gist whose exposure to the various techniques will be high. 
IMMEDIATE AND LONG-TERM FOLLOW-UP OF 500 CONSECUTIVE PATIENTS UNDERGOING PERCUTANEOUS TRANSLUMINAL CORONARY ANGIOPLASTY (PTCA)

J. Galvin, S. Leavey, A. Hennesy, M. Codd, G. Gearty, C. Daly, C. McCarthy, D. Sugrue.

Department of Clinical Cardiolgy, Mater Hospital, Dublin 7

Although the short-term outcome of PTCA is well-known, there is a paucity of information on long-term success. Using a computerised data registry, we now report the early and longterm results in the first 500 patients (587 PTCAs) undergoing PTCA in one instinution (1985-92).

Follow-up was by clinic visit, postal questionnaire or telephone interview. There were 367 men (mean age $54.85 \mathrm{y}$ ) and 133 women (mean age $59.78 \mathrm{y}$ ).

Results:

$\begin{array}{lrl}\text { Death (within 30 days) } & 9 & (1.8 \%) \\ \text { Acute M.I. (within 24 h) } & 22 & (4.4 \%) \\ \text { Emergency CABG } & 7 & (1.4 \%) \\ \text { Asymptomatic/improved } & 291 & (58 \%) \\ \text { (without a 2nd procedure } & & \\ \text { at a mean of 15.5 m) } & & \\ \text { Further intervention } & 175 & (35 \%) \\ \text { Elective CABG } & 92 & (18 \%) \\ \text { 2nd PTCA } & 83 & (16 \%) \\ \text { 3rd PTCA } & 7 & (1.4 \%) \\ \text { 4th PTCA } & 1 & \end{array}$

Conclusions: Although a majority (58\%) of patients were symptomatically improved following one PTCA, more than one third $(35.8 \%$ ) required a second intervention (PTCA or CABG).

\section{CARDIOVASCULAR HAEMODYNAMICS IN ESSENTIAL} HYPERTENSION (EH)

K. Carroll, F. Coakley, S. O'Mahony, P. A. Sullivan,

Mallow General Hospital, Mallow, Co. Cork.

Early stage hypertension is associated with a high cardiac output and heart rate, whereas in established hypertension cardiac output falls back to control values. To further define cardiovascular dynamics in hypertension, using thoracic electrical bioimpedence technology we measured cardiac index (CI,1/min/m2), stroke in$\operatorname{dex}(\mathrm{SI}, \mathrm{ml} / \mathrm{m} 2)$, systemic vascular resistance index (SVRI, dyn/ $\mathrm{sec} / \mathrm{cms} / \mathrm{m} 2$ ) as well as blood pressure (MBP, $\mathrm{mmHg}$ ) and heart rate (HR) in 18 untreated hypertensives whose mean age, weight and body surface area were similar to that of 62 heal thy control (C) subjects. Studies were carried out at rest and during bicycle ergometry.

Results: (Analysis of variance): $(* P<0.05), * * P<0.0 I)$

\begin{tabular}{lcccccc} 
& \multicolumn{2}{c}{ REST } & \multicolumn{2}{c}{$70 \mathrm{~W}$} & \multicolumn{2}{c}{$150 \mathrm{~W}$} \\
& $\mathrm{C}$ & EH & $\mathrm{C}$ & $\mathrm{EH}$ & $\mathrm{C}$ & $\mathrm{EH}$ \\
MEBP & 87 & $110^{* *}$ & 96 & $118^{* *}$ & 117 & $147^{* *}$ \\
HR & 69 & 71 & 106 & 106 & 153 & 150 \\
Cl & 4.1 & $3.6^{*}$ & 6.6 & $5.1^{* *}$ & 10.9 & $8.5^{* *}$ \\
SI & 61 & 52 & 63 & $50^{* *}$ & 72 & $57^{* *}$ \\
SRVI & 1849 & $2593^{* *}$ & 1403 & $2104^{* *}$ & 894 & $1442^{* *}$
\end{tabular}

Our findings indicate that established hypertension is associated with reduced cardiac and stroke indices, a similar heart rate, and an increased peripheral vascular resistance compared to control subjects. Pharmacological blood pressure-control should be directed at reversing these haemodynamic abnormalities. The use of angiotensin converting enzyme inhibitors in this situation would appear to be the ideal approach.

\section{EFFECTS OF SINGLE DOSE CAPTOPRIL ON EXERCISE TOLERANCE AND CARDIOVASCULAR DYNAMICS IN PATIENTS WITH ANGINA PECTORIS}

P. A. Sullivan, P. Kearney, T. Higgins

Department of Medicine, Mallow General Hospital.

ACE inhibitors lower vascular resistance and blood pressure. They also reduce myocardial oxygen consumption and may also increase cardiac output and have a coronary dilating effect by inhibition of local and circulating angiotensin $\Pi$. In a preliminary study of 21 healthy suyects given a single dose of captopril 25 mgms. we found a decrease of resting and exercise vascular resistance and blood pressure, an increase of cardiac and stroke indices and no corresponding changes of heart rate. We, therefore, evaluated the effects of single dose of captopril $25 \mathrm{mgms}$. on 19 subjects with angina pectoris (13 on anti-anginal therapy) with previously documented positive exercise tests. Primary end points were time to onset of chest pain and total exercise time using a fixed bicycle exercise protocol. Other end points included cardiac and stroke indices and vascular resistance measured by urilising thoracic bioimpedence and also blood pressure and heart rate. Subjects were studied in an open label fashion before and one hour after $25 \mathrm{mgms}$. of oral captopril.

Results: After captopril, both exercise time to onset of angina and total exercise time respectively increased 4.4 to $6.3 \mathrm{mins}$. and 5.5 to $6.8 \mathrm{mins}$., both $\mathrm{P}<0.005$. There was no significant change at rest or during exercise of cardiac or stroke indices. Blood pressure decreased but there was no corresponding change of vascular resistance other than a tendency towards a decrease. Resting and exercise heart rates fell significantly. Single dose captopril has a beneficial effecl on effort tolerance in angina pectoris consistent with enhanced coronary blood flow. The reduction of heart rate may reflect parasympathetic activity, a known effect of ACE inhibition and this too could improve effort tolerance.

\section{DOPPLER ECHOCARDIOGRAPHIC EVIDENCE OF LEFT} VENTRICULAR DIASTOLIC DYSFUNCTION IN ANK YLOSING SPONDYLITIS

J. J Crowey, S. M. Donnelly, M. Tobin, O. FitzGerald, B. Bresnihan, B. J. Maurer, P. J. Quigley.

Depts. of Cardiology and Rheumatology, University College and St. Vincent's Hospital, Dublin.

Cardiac involvement in the form of conduction abnormalities or aortic regurgitation occurs clinically in $5.10 \%$ of patients (pts) with ankylosing spiondylitis (AS) and contributes to their increased mortality. Few studies have assessed myocardial function. This study assesses the prevalence of subclinical systolic and diastolic left ventricular dysfunction in pts with AS.

Fifty-rine pts (49 males and 10 females; mean age $41.6 \pm 9.8$ years) were assessed. Mean disease duration was $17.3 \pm 8.9$ years. 44 age and sex-matched controls were also studied. All pts and controls underwent 12 lead electrocardiograph, 24 hour Holter monitoring, and 2-D, M-mode and Doppler echocardiography. Cardiac examination was normal in all.

By cchocardiography, abnormal left ventricular diastolic func- 
tion was detected in $13 \mathrm{pts}$ ( $24 \%$ ). Two patterns were seen. In $9 \mathrm{pts}$ evidence of abnormal ventricular relaxation was present. This consisted of prolonged isovolumic relaxation time, prolonged deceleration time and reversal of the peak early and late transmitra diastolic flow velocities (EIA ratio). In 4 pts a restrictive pattern was seen. These pts had an increased E/A ratio and reduced deceleration time. Mild aortic and mitral regurgitation were seen in one and five pts respectively. No abnormalities of cardiac dimensions or systolic function were noted. There was no correlation between the presence of diastolic dysfunction and age, diseae duration, disease severity or the presence of noncardiac extraarticular manifestations.

We conclude that myocardial involvement in the form of left ventricular diastolic dysfunction occurs frequently in AS pts in the absence of clinical cardiac involvement. This represents a further primary cardiac abnormality in AS and may contribute to its longterm morbidity.

\section{THE KILKENNY HEALTH PROJECT: CHANGES IN CHD} RISK FACTORS IN POPULATION SURVEYS, 1985 TO 1991

E. Shelley, C. Collins, L. Daly, I. Graham, N. Hickey, R. Mulcahy.

Scientific Committee, Kilkenny Health Project, Dean Street, Kilkenny, Ireland.

Population surveys were carried out using MONICA methodology to estimate changes in CHD risk factors during a community programme for CHD prevention. Total sample sizes of men and women aged 35 - 64 years were 791 and 802 in 1985 and 1990 respectively in Kilkenny (KK), and 604 and 631 in 1986 and 1991 in the reference county ( $R C$ ).

Mean serum total cholesterol fell by $0.09 \mathrm{mmol} / 1$ in KK men to 5.96 , and by 0.41 to 5.59 in RC; in women the drop was 0.39 $\mathrm{mmol} / 1$ to 5.64 in $\mathrm{KK}$ and 0.32 to 5.61 in RC. Mean systolic BP decreased by $3.7 \%$ in men in both counties - to $138.7 \mathrm{~mm} \mathrm{Hg}$ in $\mathrm{KK}$ and to 137.9 in $\mathrm{RC}$; in women the decrease was slightly greater in $\mathrm{KK}, 5.5 \%$ to 131.8 , than in $\mathrm{RC}, 4.8 \%$ to 129.9 . There was an increase of $0.8 \%$ in mean diastolic $B P$ in men to $79.2 \mathrm{~mm} \mathrm{Hg}$ in $\mathrm{KK}$, but a decrease of $6.3 \%$ to 77.5 in $\mathrm{RC}$; in women the decrease was $2.6 \%$ in $\mathrm{KK}$ to $75.1 \mathrm{mmHg}$, and $4.6 \%$ in $\mathrm{RC}$ to 74.7 . The decline in regular cig. smokers was less in men from $\mathrm{KK}, 1.5 \%$ to a prevalence of $25.8 \%$, than in RC, $2.7 \%$ to $26.5 \%$; in women the decrease was greater in KK, $6.8 \%$ to $22.1 \%$, than in RC, $3.5 \%$ to $23.9 \%$. The prevalence of obesity increased by $2.0 \%$ in KK men and $3.6 \%$ in $\mathrm{KK}$ women, to give prevalences of $15.5 \%$ and $23.3 \%$; the increases were greater in RC, $10.5 \%$ in men and $5.7 \%$ in women, to 1991 obesity prevalences of $24.6 \%$ and $28.3 \%$.

During the 1980s CHD mortality declined in Irish men and women. Between 1985/86 and 1990/91 CHD risk factors decreased in both counties. Mean serum total cholesterol in men and mean diastolic BP in men and women declined more in RC. Smoking prevalence in women and obesity prevalence in men and women declined more in $\mathrm{KK}$

\section{EXERCISE STRESS ECHOCARDIOGRAPHY: USE OF A} NEW TECHNIQUE IN A PERIPHERAL HOSPITAL

P. W. Johnston, J. Gibson, P. Crowe

Wards 5/6, Royal Victoria Hospital, Grosvenor Road, BT14 6RD.

In the evaluation of ischaemie heart disease, exercise stress testing was recently shown to have a sensitivity of $78 \%$ and a specificity of $65 \%$, the sensitivity improved to $100 \%$ using thallium scintography ${ }^{(1)}$. This technique, however, is not widely available in peripheral hospitals. Exercise stress echocardiography has been proposed as an alternative to thallium scanning and would be more readily accessible.

Exercise stress echocardiography was performed on 17 patients eleven with non $Q$ wave myocardial infarction, four with $Q$ wave myocardial infarction and two with atypical chest pain. Preference was given to those with non $Q$ wave infarcts hecause of the poor predictive value of exercise siress testing in this group.

Two dimensional echocardiograms were performed at rest and immediately post exercise using a digitised cine loop and side hy side analysis on all patients. The echocardiograms were assessed for reversible regional wall abnormalities by a consultant cardiologist blinded to the results of the exercise stress test.

Exercise stress tests were positive in six patients, five of whom had reversible regional wall motion abnormalities. In addition, a further four patients with negative treadmills had reversible regional wall abnormalities and one patient had a non diagnostic stress echocardiogram. Our initial experience suggest that the addition of stress echocardiography to conventional exercise stress testing in a peripheral hospital increases the detection of abnormlities and indicates patients in whom further evaluation is sequired.

Reference

1. Galanti, G., Sciagria, R. Comeglio. M. el al. Diagnostic accuracy of peak excrcise echocardiography in coronary artery discasc. Comparison with thallium - 201 myocardial scintography. Am. J. Cardiol. 1991: 122 (6): $1609-16$

EVALUATION OF MYOCARDIAL REPERFUSION AND SUBSEQUENT RECOVERY OF SEGMENTAL DYSFUNC TION WITH EXERCISE ECHOCARDIOGRAPHY

P. A. Joseph, K. Robinson, T. Kinsella, P. Crean, G. Gearty, M. Walsh.

Department of Cardiology, St. James's Hospital, Dublin 8.

Exercise echocardiography (EE) may detect abnormal wall motion (WM) and thickness in the myocardium thus revealing underlying IHD. The use of EE in the detection of improved segmental function following reperfrusion of the myocardium has, however, not been assessed.

Forty palients (pts), (males 28 , females 12 , mean age $53.6 \pm 8.7$ years) with single vessel disease and eight with multivessel disease had abnormal segmental WM and thickness in diseased coronary artery territories on EE before either PTCA of CABG

Thirty-two underwent PTCA and six months following this procedure all underwent repeat EE. 28 of $32(87.5 \%)$ had nomal WM and thickness in the target vessel territorics. On angiography. after six months, the PTCA site remained dilated in 29 of 32 $(90.6 \%)$ pls. The concordance of findings of EE with angiography was $96.6 \%$ ( $p<0.0001, \mathrm{k}=0.826$ ). To evaluate recovery time for abnormalities of WM and thickness, seven of the 32 underwent serial EE after 2 days and after 2, 4 and 6 months. Although abnormalities of WM and thickness were no different to pre PTCA values two days following reperfusion $(p=N S)$, improvement became evident at two months $(p=0.015)$. Only after six months was WM normal in the majority $(p=0.015)$.

Eight of the 40 pts underwent CABG and had normal WM and thickness on EE after six months. 
In seven of the seven age-matched controls with abnormal WM and thickness changes persisted at six months.

$E E$ is useful in the confirmation of arterial reperfusion in the long term, following either PTCA or CABG. In spite of successful reperfusion, however, normalisation of ichaemic segmental myocardial dysfunction may not be immediate and factors other than relief of major epicardial coronary obstructions may play an important role.

\section{EXERCISE ECHOCARDIOGRAPHY WITH MULTIPLE FILTERING TECHNIOUES: A COMPARISON WITH \\ EXERCISE TC 99M MIBI SPECT IN 3-D IMAGES FOR IDENTIFICATION OF MYOCARDIAL ISCHAEMIA}

\section{P. A. Joseph, K. Robinson, T. Kinsella, G. King, P. J. Freyne,} P. Crean, G. Geary, M. Walsh.

Department of Cardiology, St. James' Hospital, Dublin 8

Exercise echocardiography (EE) is useful in the detection of myocardial ischaemia but has not been compared to Technetium $99 \mathrm{~m}$ metoxyisobutylisonitrile single photon emission computed tomography in 3-D mages (Tc $99 \mathrm{~m}$ MIBI SPECT in 3-D). Fifty eight patients (males 37 , females 21 - mean age $55.9+9.4$ ) with recurrent episodes of angina of effort were studied. Abnormalities of left ventricular wall motion and thickness on $\mathrm{EE}$ and perfusion defects on Tc 99m MIBI SPECT in 3-D suggesting myocardial ischaemia were compared with coronary angiography. The results obtained with both of these techniques were then compared with each other.

The findings on EE correlated with those on coronary angiography in $52(89.7 \%$ ) of the 58 patients ( $p<0.001, \mathrm{k}=0.817$ ) EE detected 42 (87.5\%) of 48 patients with significant ( $>75 \%$ stenosis) coronary artery disease in at least one vessel on coronary angiography. All of 10 patients with normal coronary angiography had normal findings on EE (specificity 100\%).

The findings on excrcise Tc $99 \mathrm{~m}$ MIBI SPECT 3-D correlated with those on coronary angiography in $35(60.3 \%)$ of 58 patients $(p<0.001, k=0.344)$. Exercise To $99 \mathrm{~m}$ MIBI SPECT in 3-D detected $34(70 \%)$ of 48 patients with significant coronary artery disease. Ten out of 10 with normal coronary angiograms had normal exercise Tc $99 \mathrm{~m}$ MIBI SPECT in 3-D results (specificity 100\%).

The concordance of EE with exercise Tc $99 \mathrm{~m}$ MIBI SPECT in 3-D in identifying myocardial ischaemia was $63.8 \%$ ( $\mathrm{p}<0.0001$, $\mathrm{k}=0.384$ ).

Exercise echocardiography is a highly sensitive and specific noninvasive technique useful in the evaluation of patients with ischaemic heart disease. Its greater sensitivity may render it a more useful investigation than Tc $99 \mathrm{~m}$ MIBI SPECT in 3-D in the detection of underlying coronary stenoses.

EVALUATION OF PHYSIOLOGICAL EFFECTS OF CORONARY STENOSIS ON SEGMENTAL MYOCARDIAL FUNCTION; A CORRELATION BETWEEN QUANTITATIVE ANGIOGRAPHY AND EXERCISE ECHOCARDIOGRAPHY

P. A. Joseph, K. Robinson, T. Kinsella, P. Crean, G. Gearty, M. Walsh.

Department of Cardiology, St. James's Hospital, Dublin 8.

Non-invasive assessment of the effects of coronary stenoses using electrocardiography or nuclear cardiology is often unreliable and may lead to false estimates of the severity of the underlying coronary disease. Regional abnormalities of left ventricular wall motion (WM) and thickness may develop as a consequence of myocardal ischacmia and are readily detectable using exercise echocardiogr aphy (EE). To evaluate the usefulness of $E E$ in the assessment of the physiological consequences of underlying coronary artery disease, 61 patients (males 43 , females 18 , mean age $56.8+9.4$ years) with stable angina pectoris were studied. The severity of the underlying coronary artery disease was first as sessed using standard contrast angiography, Visual estimates of the percent cross-sectional narrowing of 122 coronary stenoses in the 61 patients were made. There were 8 stenoses of $<25 \%, 23$ of $25-50 \%$. 25 of $50-75 \%$, and 66 of $75-90 \%$.

All patients with stenoses $<25 \%$ in the luminal narrowing had normal WM and thickness changes on EE. Abnormalities of WM and thickness on EE were associated with 11 of 23 (47.8\%) vessels with a $25-50 \%$ stenosis, 18 of $25(72 \%)$ with $50-75 \%$ stenosis and 63 of $66(97 \%)$ with $75-90 \%$ or more stenosis. This correlation between the severity of impairment of segmental myocardial function on EE and the severity of lesions in all three major epicardial coronary stenoses was highly significant $(p<$ $0.001)$.

Conclusions: $\mathrm{EE}$ is useful in the assessment and grading of the physiological consequences of coronary stenoses. In addition, it may detect impaired myocardial function even in the presence of stenoses which are not angiographically regarded as being obstructive to antegrade coronary flow.

\section{HIV AND CARDIAC DISEASE IN IRELAND: AN ECHOCARDIOGRAPHIC PROFILE}

B. McAdam. G. King, R. Sheahan, N. El Gaylani, A. Simpson,

I. Temperley, F. Mulcahy, G. Gearty, P. Crean, M. Walsh

Depts. of Cardiology, Haematology and Genitourinary Medicine, St. James's Hospital, Dublin 8.

Our hospital is the only centre for the treatment of HIV related ilness in the Republic of Ireland. The aim of this study was to assess the prevalence of cardiac pathology in consecutively admitted patients with AIDS using 2D and doppler echocardiography (ECHO). We studied 101 paticnts (68 males and 33 females with an age range $22-52$ yrs). All risk groups were represented. Seventy-one (70\%) had stage IV disease.

A total of three patients had abnormal ECHO findings (33.7\%). Global systolic ventricular dysfunction (ejection fraction $<35 \%$ ) was observed in 15 patients (14.7\%). Of these only three had left ventricular chamber dilatation and 14 had stage IV disease. Iso. lated right ventricular dysfunction occured in 13 patients and was confined to the drug abusing group. Pericardial effusions were detected in 14 patients, one of whom had cardiac tamponade. $V$ alvular abnormalities were noted in nine patients, two of whom had tricuspid valvular endocarditis.

In summary, echocardiographic abnormalaties are common in HIV infected patients (33.7\%) and occured predominately in stage IV disease $(82.4 \%)$.

We recommend echocardiography be performed as part of the routine investigations on all HIV infected patients admitted to hospital with advanced disease. 


\section{EMPLOYMENT STATUS FOLLOWING CORONARY ARTERY BYPASS GRAFT OR PERCUTANEOUS TRANSLUMINAL CORONARY ANGIOPLASTY}

H. M. McGec, T. Graham, B. Crowe, J. H. Horgan Department of Cardiology, Beaumont Hospital, Dublin 9.

This study examined employment status following Coronary Artery Bypass Graft (CABG) or Percutaneous Transluminal Coronary Angioplasty (PTCA) for coronary artery disease (CAD). Patients undergoing CABG or PTCA, six to 18 months previously were interviewed ( $M=176$ males; $92 \%$ response).

Pre-Treatment Characteristics

M

Mean Age (s.d.)

Smoking (\%)

Employed (\%)

Angina Symptoms (\%)

Post-Treatment Characteristics

Angina Symptoms (\%)

Return to Work: overall sample (\%)

- Those with angina post-treatment (\%)

- Those without angina post-treatment (5)

Life Style: Smoking (\%)

- Take regular exercise (\%)

Cholesterol Check since CABG/PTCA $(\%)$

- Completed Cardiac Rehabilitation (\%) 30

* $\mathrm{P}<.05 \quad$ ***P $<.01 \quad * * * \mathrm{P}<.001$

Despite more pre/post-treatment angina, the PTCA group were significantly more likely to resume employment. Conversely more CABG patients undertook positive lifestyle activities. Treatment type (CABG or PTCA) is associated with differing levels of return to work for $\mathrm{CAD}$ patients.

\section{CARDIOPULMONARY BYPASS: NORMOTHERMIA OR HYPOTHERMIA?}

J. McGinley, J. Hurley, E. McGovern, M. Neligan

National Cardiac Surgery Unit, Mater Hospital, Eccles Street, Dublin 7.

AB results with present day cardiopulmonary bypass are so good in terms of clinical endpoints, any change in technique including the use of normothermia has to be judged objectivly using physiological or biochemical endpoints. Because of a recent trend in cardiac surgery towards normothermic cardiopulmonary bypass (CPB the aim of this study is to determine the effect of normothermic CPB on oxygen flux and lactate production, parameters which are directly related to tissue oxygenation. In a controlled prospective randomised study, patients were divided into five groups of twelve patients each and the CPB in each group was managed at a different temperature or flow. Group A: cooled to 25 degrees during CPB and flow maintained at $2.4 \mathrm{~L} / \mathrm{min} / \mathrm{m} 2$, Groups $B$ and C: 28 degrees at 2.4 and $3 \mathrm{~L} / \mathrm{min} / \mathrm{m} 2$ respectively. Groups D and E: 37 degrees at 2.4 an $3 \mathrm{~L} / \mathrm{min} / \mathrm{m} 2$ respectively. Serum lactate levels were measured and the parameters of oxygen delivery (D02), and oxygen consumption (VO2) were calculated at ten minute intervals during CPB. The results show that V02 was significantly lower in the hypothermic groups and that while it was possible to significantly increase D02 relative to baseline during hypothermic and normothermic CPB, this was not accompanied by a rise in VO2 at hypothermia. This supports the concept of a biphasic relationship between $\mathrm{DO} 2$ and VO2 and suggests that the "critical DO2", that is the level of DO2 at which the VO2 reaches a maximum, is lower during hypothermia. There was no significant difference in lactate production in the groups maintained a normothermia versus the groups at hypothermia either at 2.4 or 3 $\mathrm{L} / \mathrm{min} / \mathrm{m} 2$. Therefore while hypothermia reduces oxygen demand of tissues, the patier.ts maintained at normothermia did not suffer an oxygen debt as evidenced by a lack of significantly higher lactates and this may be partly explained by a higher critical DO2 at normothermia. In conclusion we found no detrimental effect of normothermic CPB on peripheral tissue oxygenation.

\section{CARDIAC SURGERY WAITING LIST DEATHS}

C. Austin, J. Cleland, D. Gladstone, H. O'Kane. Department of Cardiac Surgery, Royal Victoria Hospital Grosvenor Road, Belfast BT12 6BA.

The urgent demand for cardiac surgery, especially for ischaemic heart disease (IHD), far exceeds the ability of most units to mee it. With a waiting list in excess of 1,000 patients, deaths on the waiting list seem inevitable. In an effort to reduce these deaths we have reviewed waiting list mortality over a period of 30 months from January 1990 to June 1992, to try to establish whether or not the clinical profile could alert us to a case type other than those of which we are already aware eg left main stem lesion. In a total of 85 deaths, 65 (76.5\%) occurred in the IHD group and $25(23.5 \%)$ in patients with valvular disease; of the latter group $13(65 \%)$ had aortic stenosis, $2(10 \%)$ had aortic incompetence, $5(25 \%)$ had mixed mitral disease. Of the IHD group, $51(79.7 \%)$ were males with an average age of 60 years (range $40-74$ years) and $14(20.3 \%$ ) were female with an average age of 59 years (range 48-69 years) The interval for death was calculated from the date of cardiac catheterisation. This was an average of 14.4 months (3 days-57 months) for the males and 13.9 months ( 10 days -57 months) for the females. A high risk group was identified as dying earlier, $\mathbf{n}=25$ $(38.5 \%)$. This group was found to contain those with unstable angina or symptomatic patients reporting frequent angina to the hospital. In this group the average time was 9.79 months for males, (range 3 days- 41 months) compared to 17.7 months (range 1 month-57 months) for less symptomatic patients, the time was 4.26 months (range 10 days -14 months) compared to 18.3 months ( 2 months -57 months) for the females. We believe that those patients reporting frequent angina and unstable angina should be prioritized for surgery.

Despite our aw areness of aor tic stenosis as a high risk group we were diappointed to find that we lost so many (13 patients) over a 30 month period.

\section{HEART AND HEART AND LUNG TRANSPLANTATION} FOR ADULT CONGENITAL HEART DISEASE

J. O'Sullivan, A. Hasan, J. R. L. Hamilton, S, Hunter, C. J. Hilton J. H. Dark.

Department of Paediatric Cardiology, Freeman Hospital, High Heaton, Newcastle upon Tyne, NE7 7DN, England.

Patients with congenital heart disease who survive beyond childhood present difficult problems when they become symptomatic in adulthood. Correction of the underlying lesion is often 
impossible and some form of transplantation provides the only possibility of survival. We report our experience of transplantation in this high risk group.

Since 1986 nine patients have undergone orthropic heart transplantation (age range 16-61). The diagnoses were complex in six patients, failed tetralogy of Fallot repair one patient, failed Fontan procedure one patient, and failed Mustard procedure one patient. There were four early postoperative deaths $(44 \%)$ with no deaths after follow-up of 2.3 yrs (range $0.5-3$ years). The cause of death was multisystem failure and haemorrhage in three motibund patients and lung sepsis following incomplete restoration of anomalous pulmonary venous drainage in one patient. Nine patients underwent heart lung transplantation (age range 16-41, median 35 years), the diagnoses were large left to right shunts with irreversible pulmonary hypertension in 7 cases and pulmonary atresia. ventricular septal defect with multiple collateral vessels in two. Two (22\%) died in the early post operative period. One patient died six months post transplant.

Adult patients with congenital heart disease usually have debilitating symptoms when offered for transplantation. Previous surgery, distorted pulmonary arteries and anomalous pulmonary and systemic venous connections pose technical difficulties. Early mortality (33\%) is high but over $60 \%$ of this high risk group can be offered significant improvement in quality of life.

\section{DOES CARDIOPULMONARY BYPASS CAUSE NEUROPSYCHOLOGICAL DEFICIT?}

C. M. McDaid, A. S. Phillips, S. A. Lewis, T. J. McMurray, H. O'Kane.

Departments of Mental Health, Anaesthetics \& Cardiac Surgery, The Queen's University of Belfast \& Royal Victoria Hospital Belfast.

Evidence suggests that there may be considerable deficit in cognitive functioning after cardiopulmonary bypass (CPB). Reported estimates of the incidence range from $30-80 \%$. It has been argued that this deficit is greater in valve replacement (VR) than in coronary artery bypass graft surgery (CABG). The failure by many studies to use a standardised CPB regeme and neuropsychological analysis makes comparisons between studies difficult.

A strict CPB protocol was used in all cases using a Polystan bubble oxygenator with crystalloid prime. During bypass a constant flow rate was maintained, mean perfusion pressure was kept between $40-60 \mathrm{mmHg}$ and $\mathrm{pO} 2$ between $100-200 \mathrm{mmHg}$ using alpha stat criteria.

Forty-one CABG and 19 VR patients were assessed with a cognitive batcery pre-operatively, day 2 and day 7 post-operatively. Using ANOYA and regression analysis, the main findings were:

- There were presurgical differences between the VR and CABG groups which persist at day 7 .

- VR do not differ from CABG in consequences of surgery.

- For the most part, by day 7 cognitive functioning had returned to pre-operative levels in both groups.

- Perioperative variables (eg duration of bypass), which have been argued to cause cognitive deficit were found to be poor predictors of cognitive functioning in comparison to psychological variables.
FIVE YEAR FOLLOW-UP OF PATIENTS FOLLOWING ISOLATED CORONARY ARTERY BYPASS SURGERY IN IRELAND, 1983-1985

M. Lonergan, L. Daly, I. Graham.

lrish Cardiac Surgery Register and Cardio-thoracic Surgeons, National Cardiac Surgery Unit.

M. Lonergan. Irish Cardiac Surgery Register, Baggot Street Community Hospital, Baggot St., Dublin 4

The Irish Cardiac Surgery Register is unique internationally in collecting follow-up information on a national basis on all patients following Cardiac Surgery.

In the three years, 1983-1985 primary isolated coronary artery bypass graft surgery was carried out on 1533 patients. Overall five year mortality, including operative deaths was $10.7 \%$.

Late mortality [i.e. deaths occuring between 30 post-operative days and 5 years] was $7.6 \%$. Females had lower late mortality than males $[6.1 \%$ vs $7.8 \%$; ns]. Factors significantly related to late deaths were severity of pre-op angina**, type of angina*, any history of myocardial infarction*, clinical and investigative evidence of reduced left ventricular function***, non-use of an internal mammary artery [IMA]* graft and smoking in the three months prior to surgery*.

At five year follow-up, $69.0 \%$ of patients were angina free, while 6.4\% had Canadian Cardiov ascular Society [CCS] grades 3 4 angina. When compared to pre-operative level of angina $90.0 \%$ of patients had improved anginal status.

This Irish Cardiac Surgery Register report provides unique and valuable follow-up information on a non-selected rational cohort of patients five years after coronary artery bypass graft surgery and allows an unbiased assessment to be made of the late results of this procedure. To the best of our knowledge no such information is available elsewhere.

*, ${ }^{* *}, * * *$ - Levels of significance using chi-squared tests.

\section{ARTERIAL DUCT PATENCY IN NEONATAL LAMBS FOLLOWING RADIOFREQUENCY THERMAL BALLOON ANGIOPLASTY}

K. P. Walsh, S. E. Abrams, M. Diamond, M. J. Clarkson. Cardiac Dept, Alder Hey Hospital, Liverpool L12 2AP, and

Veterinary Field Station, Liverpool University, UK

Introduction: Maintaining long term arterial duct (AD) patency offers potential therapeutic advantages in duct dependent congenital heart lesions. Balloon angioplasty alone has been shown to maintain patency for limited periods. By altering collagen binding and denaturing smooth muscle cells a heated balloon theoretically might prevent ductal occlusion.

Method: We treated the AD of 25 neonatal lambs with radiofrequency thermal balloon (RFTB) angioplasty to assess efficacy, 3 others had angioplasty alone. Mean age at treatment 34 hrs (8-72 hrs), mean weight $3.8 \mathrm{~kg}(2.0-5.0 \mathrm{~kg})$. In anaesthetised lambs, a $5 \mathrm{~mm}(n=13)$ or $6 \mathrm{~mm}(\mathrm{n}=1 \mathrm{l})$ RFTB catheter was passed transvenously across the AD. The RFTB was inated to 4 atmospheres and radiofrequency applied. Temperatures were maintained for $15 \operatorname{secs}$ at $65^{\circ}(n=2), 75^{\circ}(n=2), 85^{\circ}(n=9), 100^{\circ}(n=9)$, $120^{\circ}(n=3)$. Lambs were recatheterised at intervals to assess patency and quantify the shunt.

Results: Mean follow up is 58.8 days (21-107 days), One $2 \mathrm{~kg}$ lamb died from heart failure 24 hours post procedure. Only 1 of 3 angioplasty alone ducts remains just patent at 107 days, whereas in 
the treated group $19(79 \%)$ of 24 ADs remain patent at last follow up. Mean minimum ductal diameter at last follow up is $3.03 \mathrm{~mm}$ (1.4-5.09). Mean Qp:Qs is 2.06 (1-4.15). Neither ductal diameter nor shunt size correlates with balloon size and temper ature.

Conclusion: RFTB angioplasty maintains AD patency in lambs for at least 15 weeks.

\section{QUANTITATIYE ANGIOGRAPHIC MORPHOLOGY OF RESTENOTIC LESIONS AFTER PTCA - INSIGHTS TO THE RESTENOSIS PROCESS}

D. P. Foley, W. R. Hermans, B. J. Rensing, W. Rutsch, H. Emanuelsson, N. Danchin.

W. Wijns, F. Chappuis, P. W. Serruys, for the MECATOR group

Thoraxcentre, Erasmus University Ee 2332, PO Box 1738, 3000 DR Rotterdam, Netherlands.

Backround: Fifteen years after its inception into clinical practice, restenosis is still the 'Ahilles heel' of percutaneous transluminal coronary angioplasty (PTCA). Clinical studies of pharmacological agents or new devices for the prevention/control of restenosis highlight the "restenosis rate" as defined by categorical angiographic criteria. In attempts to identify factors predictive of restenosis, pre-PTCA lesion morphology has become the focus of much interest but little attention has been paid to morphology of the restenotic lesion itself.

Aim, Methods and Results: The aim of this study was to determine if there are actual morphological differences between the "restenotic" lesion 6 months after PTCA, and the original stenosis, which might provide some new insight to the underlying pathological process. The study population comprised all 663 patients (778 lesions) in the MERCATOR trial, who had angiographic follow-up (94\%). Minimal Luminal Dianeter (MLD), Diameter Stenosis (\%DS), Vessel Size/reference diameter (RefD,mm), Lesion Length (LL,mm), Plaque Area (PA,mm2), Symmetry Index and Balloon Inflated Vessel Segment (BIVS, ie. mean diameter (mm) of the entire segment dilated) were measured using an automated edge detection technique. Restenosis was defined according to two fundamentally disparate categorial critria: 1) 1oss of $\pm 0.72 \mathrm{~mm}$ in MLD during follow-up (Fup) ( $n=128$, restenosis rate 20\%) which identifies a significant deterioration in luminal diameter during follow up, 2) $>50 \%$ DS at Fup (n $=231$, restenosis rate $35 \%$ ) which does not convey any measure of the degree of luminal change, being based, instead, on historical physiological principles. Paired t-tests were used to identify differences between the restenotic lesion and its original baseline morphological characteristics. P values $<0.05$ were considered significant:

\begin{tabular}{|c|c|c|c|c|}
\hline & \multicolumn{2}{|c|}{$(0.72):$} & \multicolumn{2}{|c|}{ (>50\% DS): } \\
\hline & Pre & Fup & Pre & Fup \\
\hline MLD & $0.89 \pm 0.43$ & $081 \pm 0.58$ & $091 \pm 0.39$ & $0.95 \pm 0.49$ \\
\hline RefD & $2.70 \pm 0.51$ & $2.61 . \pm 0.55^{* *}$ & $2.63 \pm 0.48$ & $2.72 \pm 0.52^{* *}$ \\
\hline \%DS & $67 \pm 16 \%$ & $69 \pm 21 \%$ & $65 \pm 14 \%$ & $65 \pm 15 \%$ \\
\hline LL & $6.07 \pm 2.18$ & $6.83 \pm 2.14^{* *}$ & $6.17 \pm 2.36$ & $6.6 \pm 2.23 * *$ \\
\hline PA & $7.06 \pm 3.48$ & $7.44 \pm 3.44^{*}$ & $7.02 \pm 3.96$ & $7.67 \pm 3.64^{* *}$ \\
\hline BIVS & $2.22 \pm 0.78$ & $1.89 \pm 1.03^{* *}$ & $2.16 \pm 0.67$ & $2.0 \pm 0.85^{* *}$ \\
\hline
\end{tabular}

Despite deteriorating during follow up to no greater an obstruc tion than at baseline, in terms of MLD and DS. The restenotic lesion becomes longer and covers a greater plaque area than prePTCA. Decrease in the reference diameter and mean diameter of the segment dilated are also unveiled if " $0.72 \mathrm{~mm}$ " is used as the restenosis criterion whereas ">50\% DS" intimates that reference diameter of the restenotic lesion actually increases.

Conclusion: These findings suggest that the allegedly "controlled injury" at PTCA provokes a proliferative response, not only in the lesion, but also in the adjacent, presumed "normal" vessel wall, causing a diffuse narrowing of the entire segment, which is detectable by quantitative angiographic analysis. \%DS measurements, requiring the assumption of a "normal" reference segment therefore, fail to accurately reflect changes in lesion morphology in the months following PTCA. Similarly, restenosis criteria which do not convey a measure of the extent of renarrowing after intervention are of doubtful value for the purposes of evaluating the effects of pharmaco-biological agents, or new devices, for the prevention or control of luminal renarrowing/restenosis . 